\title{
AN EVALUATION METHODOLOGY FOR THE SELECTION OF AN INTERCHANGE CONFIGURATION
}

DECEMBER 1973 - NUMBER 29

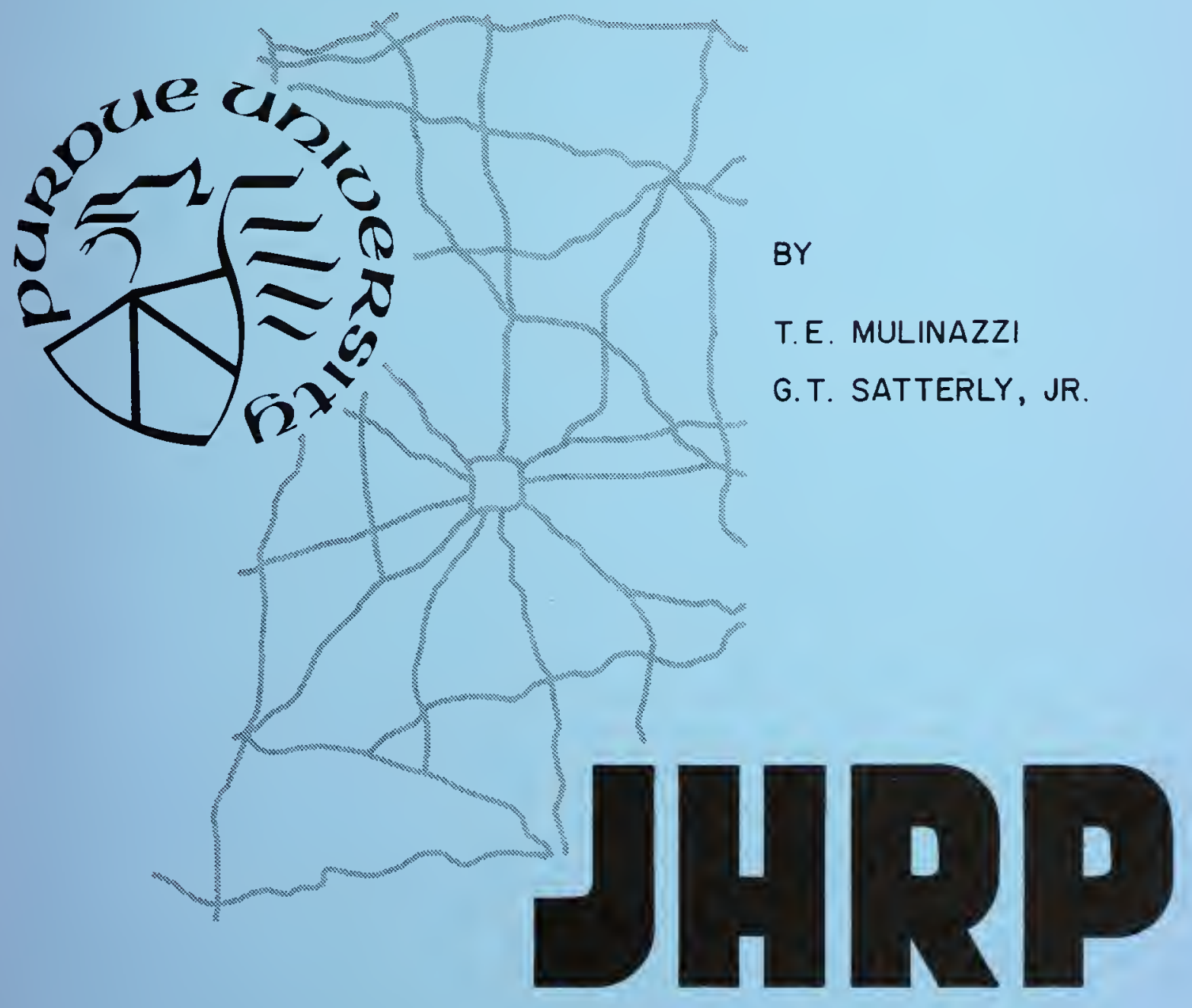

JOINT HIGHWAY RESEARCH PROJECT PURDUE UNIVERSITY AND 



\section{AN EVALUATION METHODOLOGY FOR THE SELECTION OF}

\section{AN INTERCHANGE CONFIGURATION}

T0: J. F. McLaughilin, Director

Joint Highway Research Project

FROM: H. L. Michael, Associate Director Joint Highway Research Project

Project: $\quad C-36-68 C$

File: $\quad 3-6-3$

The attached Techntcal Paper "An Evaluation Methodology for the Selection of an Interchange Configuration" has been authored by Messrs. Thomas E. Mulinazzi, formerly on our staff, and Gilbert T. Satterly, Jr., Research Engineer on our staff. The paper is a summarization of the evaluation methodology presented in the Final Report "Guidelines for the Selection of an Interchange Configuration" which was presented to the Board in September 1973.

The paper is to be presented at the 1974 Annual Meeting of the Highway Research Board in January 1974. It is submitted to the Board for approval of publication by the Highway Research Board in one of its Records during 1974.

Respectfully submitted,

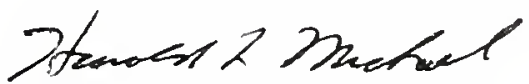

Harold L. Michael Associate Director

$H L M: m w$
CC: W. L. Dolch
R. H. Harrell
C. F. Scholer
R. L. Eskew
M. L. Hayes
M. B. Scott
G. D. Gibson
C. W. Lovell
J. A. Spooner
W. H. Goetz
G. W. Marks
N. W. Steinkamp
M. J. Gutzwiller
R. D. Miles
H. R. J. Walsh
G. K. Hallock
G. T. Satteriy
E. J. Yoder 
Digitized by the Internet Archive in 2011 with funding from

LYRASIS members and Sloan Foundation; Indiana Department of Transportation 
AN EVALUATION METHODOLOGY FOR THE SELECTION OF

AN INTERCHANGE CONFIGURATION

\author{
by \\ Dr. Thomas E. Mulinazzi \\ University of Maryland \\ and \\ Dr. Gilbert T. Satterly, Jr. \\ Purdue University
}
Joint Highway Research Project
Project: $C-36-68 \mathrm{C}$
File: $\quad 3-6-3$

A paper submitted to the Highway Research Board for presentation at the 53 rd Annual Meeting, Washington, D. C., January 1974.

\author{
Purdue University \\ West Lafayette, Indiana \\ December 13, 1973
}


AN EVALUATION METHODOLOGY FOR THE SELECTION OF

AN INTERCHANGE CONFIGURATION

\author{
by \\ Thomas E. Mulinazzi \\ and \\ Gilbert T. Satterly, Jr.
}

\title{
ABSTRACT
}

The evaluation methodology for selection of an interchange configuration which is presented in this paper is divided into four parts: 1) scrutinize the evaluation criteria to determine which ones are relevant; 2) estimate the inftial cost of each reasonable alternative interchange design; 3 ) develop an Effectiveness Profile for each such alternative design; and 4) compare the initial cost and the Effectiveness Profile for each alternative design and then select an interchange configuration.

The selection of pertinent evaluation criteria is fundamental to the evaluation methodology. The criteria chosen should measure differences between the alternative interchange designs. 
If no such criteria exist, then there is no difference between the alternative designs and the interchange configuration with the lowest initial cost should be selected.

The initial cost was used as the cost indicator for each alternative interchange design. The inftial cost was selected because it is easily obtainable and does not include some of the uncertaintles associated with the calculation of road-user costs.

The next step in the evaluation methodology is the development of an Effectiveness Profile for each alternative interchange design. An Effectiveness Profile is a graphical technique which shows each alternative's effectiveness rating for every evaluation criterion. It is based on the costeffectiveness approach of economic analysis and is the accumulation of several cost-effectiveness plots into a single graph.

The final step in the evaluation methodology is to analyze the inftial cost and the Effectiveness Profile for each alternative interchange configuration. This analysis will provide the decision maker with the necessary information to select an adequate interchange conflguration for the given conditions. 


\section{INTRODUCTION}

Interchanges are the weak links in any freeway system because of the vehicular turbulence associated with the inherent merging, diverging and weaving maneuvers. If the interchanges operate efficiently then traffic on the freeway will probably flow smoothly.

It does not seem probable that many more miles of new freeway will be built, especially in urban areas. However, those that are built will have to pass a stringent test from the ecologists. The same is true for the rehabilitation of existing freeways, which have become corridors lined with intense land deveropment. Many of the existing interchanges need upgrading and yet, with the adjacent land development, there is no easy way to alter these interchange configurations. An interchange's impact on the community and its traffic operational requirements are opposing forces with which the interchange design engineer must work. He must somehow relate these two forces and arrive at an acceptable interchange configuration. This is the most difficult part in the design of an interchange.

\section{Interchange Selection Process}

The purpose of this paper is to present an evaluation methodology that will assist the practicing design engineer in selecting an interchange configuration for a particular location. The total decision-making process recommended to select an interchange type is 111 ustrated in Figure 1. This chart shows that the interchange design engineer should be involved not only 


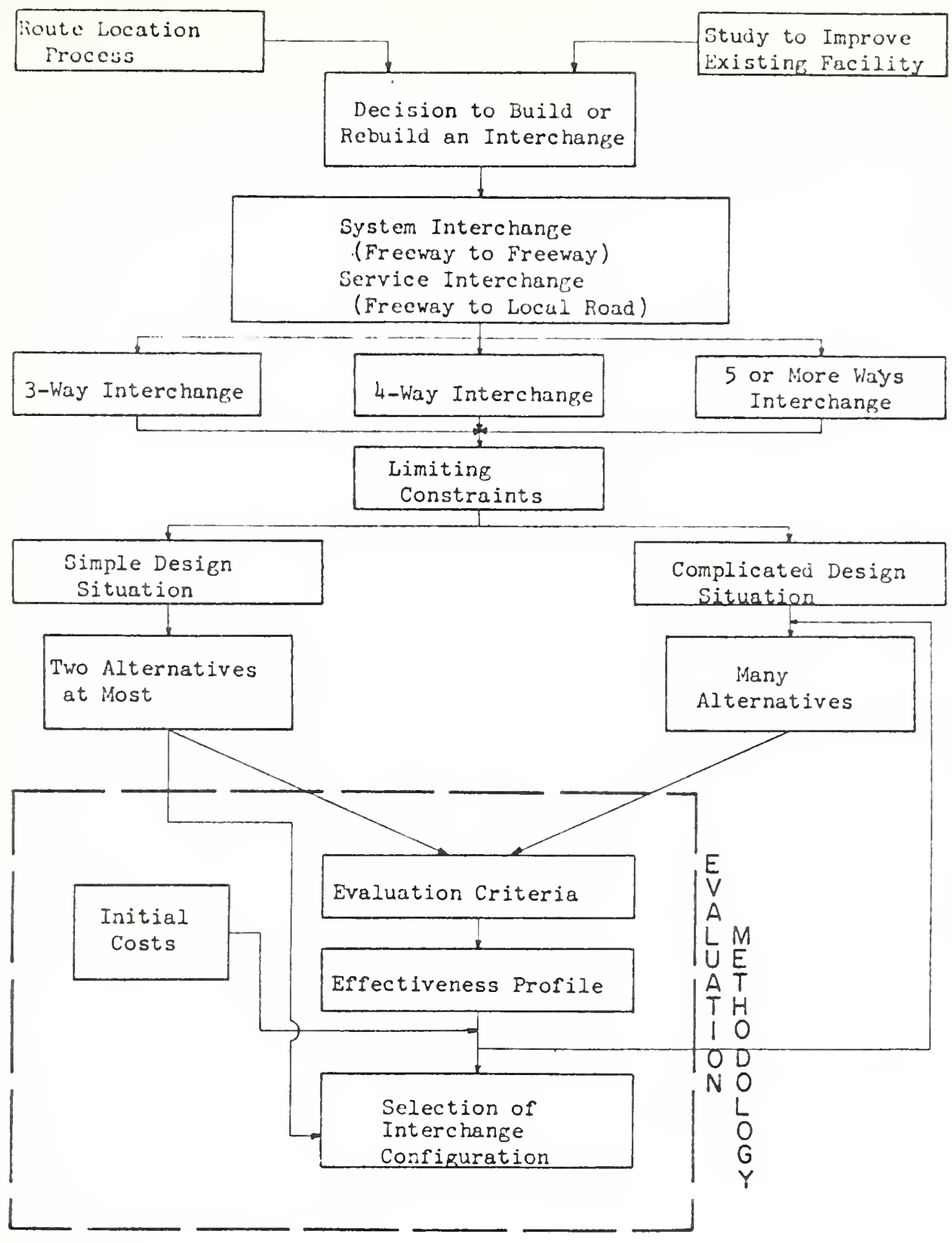

FIGURE 1. INTERCHANGE SELECTION PROCESS 
in the route location study for a new facility but also in the planning study for the rehabilitation of an existing facility. The interchange design engineer can provide valuable inputs into both of these preliminary highway design phases by evaluating the feasibility of the interchange locations and developing preliminary interchange types for these locations. The involvement of the interchange design engineer at these stages will help to minimize the situations where an adequate interchange cannot be built because of predetermined constraints.

Once the determination is made that an interchange is needed, the first step is to determine if a system interchange or a service interchange is required. A system interchange must have all free flowing ramp terminals for the quick transfer of trafflc from one freeway to another.

A service interchange, a freeway to local road connector, usually has stop-controlled or signal controlled ramp terminals on the crossroad; but in certain areas, free flow ramp terminals may be desirabie. This division into either a system interchange or a service interchange reduces the set of possible interchange configurations that can be used in any given location.

The number of possibie interchange configurations is still further reduced by classifying the desired interchange by the number of approach legs or streets: three-way; four-way; and five or more ways. The following list contains the interchange types which are applicable, based on the number of approach legs and the classification of the crossroad. 
1. Three-way interchanges (three approach roads)

A. System Interchange

2. Directional "T" or "Y"
2. Trumpet A
3. Trumpet B

B. Service Interchange

1. Directlonal "T" or "Y"

2. Trumpet $A$

3. Trumpet $B$

4. Half Diamond

5. Hybrids*

II. Four-way interchange (four approach roads)

A. System Interchange

1. Directional without loop ramps

2. Directional with loop ramps

3. Cloverleaf with $C-D$ roads

B. Service Interchange

1. Directional with loop ramps

2. Cloverleaf with $C-D$ roads

3. Parcio $A-4$

4. Parclo A

5. Parclo B-4

6. Parclo B

7. Parclo $A-B$

8. Diamond with its many variations

9. Hybrids*

11. Five or more way interchange (five or more approach roads)

A. System Interchange

1. Directional without loop ramps

2. Directional with loop ramps

3. Hybrids* (local ramps within a system inter change

B. Service Interchange

1. Directional with loop ramps

2. Rotary**

3. Hybrids*

* Hybrids are interchange configurations which do not exactly fit any of the standard interchange configurations discussed so far in this paper. Hybrids are modifications of the basic types of interchanges; the modifications are made to meet existing constraints.

**Rotary interchanges are not discussed in this paper. Rotary interchanges should not be used in this country because of the operational problems associated with their built-in weaving maneuvers. 
After narrowing the population of possible interchange types by the functional classification of the interchanging factitities and the number of approach roads, the designer should then determine if the design location has any limiting constraints on the interchange configuration. The existing land use in one quadrant may force the designer to completely avoid that quadrant when laying out the alternative interchange designs. For example, parks, schools and other public land are bypassed, if possible. The presence of frontage roads also limits the type of interchange. With a two-way frontage road system, partial interchanges are developed though the use of buttonhook ramps. ' Likewise, sip ramps are appropriate to connect the freeway to a one-way frontage road network. Interchanges with loop ramps are not readily adaptable to a frontage road system. The presence of a natural or man-made obstruction greatly influences the type of interchange. A river or rallroad paralleling the crossroad can force all of the ramps to be located in two quadrants on the same side of the crossroad.

The next step is to determine if the particular design problem under study is a simple design situation or a complicated design situation. A simple design situation would require only one or possibly two alternative interchange designs. Even with a simple or clear cut design location it is recommended that

tThere are many disadvantages associated with buttonhook ramps. They are usually the "second best" solution, difficult to sign, induce wrong way movements when ramps are isolated, and require low design speeds. Buttonhook ramps should be avoided if possibie. 
two alternatives be developed and compared. An example of a simple design situation is a service interchange between an interstate route and a low volume secondary state highway where access is needed because of the long distance between adjacent interchanges. In this case, a diamond interchange would probabiy be designed. Most interchange designers would find it difficuit to justify the time and expense of deveroping another alternative interchange configuration; and would consider it a waste of effort to use any detailed evaluation methodology. The interchange design engineer is encouraged, however, to look over the list of evaluation sriteria presented later in this paper to make sure the design situation is truly simple.

Several alternative Interchange designs are developed when a complicated design situation is encountered. The number of alternatives usually varies from two to about ten, depending on the complexity of the design problem. The major obstacles involved in interchange design are in urban areas where development has aiready occurred and the impact on the environment, or the surrounding land, is feit the most. It is also in the urban areas where some of the early freeways are becoming obsolete and in need of rehabilitation. These highly congested routes have become coirridors of high land development because of the accessibility afforded by these freeways. To correct the substandard acceleration and deceleration lanes, the closely spaced interchanges and the congested ramp movements, serfous trade-offs have to be made between the community 
Impact factors and the traffic operational factors. The following evaluation methodology is proposed to compare these two dichotomous set of factors.

\section{Evaluation Methodology}

The evaluation methodology has the following segments:

1. The interchange design engineer should scrutinize the given ilst of evaluation criteria to determine which are pertinent to the design situation under study and which factors should be added.

2. The interchange design engineer should estimate the Inftial cost for each alternative interchange design. The initial cost should include

a. construction costs

b. right-of-way costs

c. relocation costs

3. The interchange design engineer should develop an Effectiveness Profile for each alternative interchange design.

4. The interchange design engineer should compare the Inftial cost of each alternative design to $1 t^{\prime} s$ Effectiveness Proflle and select the most cost effective interchange configuration. If the interchange design engineer doing the work cannot make the final decision on the interchange type then he should present the inftial cost information and the Effectiveness Profile data to the deciston maker. 
Scrutinize the List of Evaluation Criteria

There are many criterion which should be considered to some degree in selecting an interchange type and it is easy to overlook some. Table 1 is a partial list of evaluation criterion that should be considered in the design of every interchange. These baslc criteria include measures of the traffic operational capabilities and design characteristics of an interchange. If certain minimum traffic operational constraints are not met, there is no reason to further consider that interchange configuration. For example, each of the alternative designs must be able to carry the forecasted traffic volumes.

The fndividual designer may have a partfcular measure or measures which he has used in the past as operational and design criteria for the selection of an interchange configuration. The following are some of these additional criteria:

1. Travel time

2. Travel distance

3. Radius of curvature

4. Ramp grades

5. Topography

6. Sol1 conditions

7. Dratnage

8. Spacing of interchanges

9. Design speed

10. Composition of traffic

11. Operating costs - running costs (fuel, tires, oil, matntenance)

12. Level of service 
Tabie 1

Interchange Design Criteria

1. OPERATIONAL AND DESIGN FACTORS

A. Level of service continuity between the main line and the ramps

B. Level of service continuity on the crossroad through the interchange area

C. Safety

7. Uniformity of flow

2. Accident potential

D. Unfformity

1. On and off-ramp design

2. Route continulty

3. Signing

E. Flexibility

1. Basic number of lanes

2. Lane balance

3. Stage construction

4. Maintenance of traffic during construction

$F$. Number and length of weaving sections

G. Others-depending on the design situation and the designer's experience

II. COMMUNITY IMPACT FACTORS

A. Number of acres taken outside of the main-line rightof-way

B. Number of families relocated

C. Number of commercial establishments relocated

D. Number of tax dollars removed from the tax rolls

E. Number of local streets closed

F. Taking of a particular parcel of land

1. Church

2. School

3. Historical landmark

4. Public land

5. Other

G. Lack of access to adjacent property

H. Others-depending on the design situation, designer's experience and community feelings 
The communtty impact factors should be individualized for each interchange destgn; so no set of criteria is recommended as a minimum measure of the impact upon the community from the various alternative interchange conflgurations. The objective is to minimize the detrimental community impact while maximizing the traffic operational capabilities of the interchange. Tradeoffs between these two dichotomous interchange consequences are always present.

Table 1 contains several of the more prevalent community impact factors. Additional factors include noise and air pollution, local street connectors, landscaping opportunities, land development opportunfties, local planning values, barrier effects and aesthetics.

These lists of operational and design factors and communtty impact factors are intended to be open-ended because it is Impossible to include in this paper all of the factors which could influence the selection of an interchange configuration. The designer should anticipate the evaluation criterla considered important by the public and include these in the evaluation process. The important thing is to include the factors or evaluation criteria which affect the possible interchange type. Without a set of evaluation criteria as a foundation to measure the differences between the alternative interchange configurations, the proposed evaluation methodology is weak at best. 
Develop the Inttial Cost for Each Alternative Interchange Design

The initial cost of each alternative interchange design is selected as the cost figure to use in the evaluation methodology, because it is easily obtainable and does not include some of the uncertainties assocfated with calculating road user costs. Included in the initial cost are the following items:

1. Construction costs

2. Right-of-way costs

3. Relocation costs

a. uttitities

b. families and businesses

Road-user costs are not included in the determination of the cost of each alternative design because of the problems associated with calculating dollar values. Arriving at a value for time, the accumulation of small increments of time and the uncertainty associated with the monetary value of a fatality are some of these questionable areas. It is also felt that the road-iser costs would not be significantly different for the alternative interchange configurations.

If the designer feels that some measure of road-user costs should be included in the evaluation process, he could always include it as an evaluation criterion. For example, the present worth of operating cost could be included in the analysis as a measure of the effectiveness of the alternative designs: the lower the operating cost then the more attractive will be thatalternative design. The designer should make an honest attempt, however, to accurately determine the operating cost. 
He should not take the average of the existing annual traffic and the projected annual traffic as the yearly traffic over the Iife of the project and apply the fuel, oil, maintenance, etc. factors. Operating costs not only vary over the duration of the project and the increase in traffic but also by the hour of the day.

Maintenance costs are not included because again it is feit that it would be better to include them as an evaluation criterion.

Development of an Effectiveness Profile

A technique is needed to compare the impact of the alternative interchange designs based on qualifiable as well as quantifiable criteria. There are several approaches that this evaluation procedure could take. It can simply be a rote process, similar to the interchange design table found in one of state highway design manuals. This technique of interchange conflguration selection leaves nothing to the design engineer's imagination or Ingenuity. The designer simply goes to a predeveloped table or chart and selects an acceptable interchange configuration.

One form of evaluation methodology applies economic measures such as the benefit cost ratio, rate of return, or net present worth. These techniques are primarily based on 1) first costs such as cost of construction and right-of-way costs, and 2) on motor vehicle operating costs, such as costs assoclated with accidents, delays, and travel time costs. The 
alternative with the "best" ratio or economic index is the selected interchange configuration.

Another technique, a form of which is applied by Leisch', uses a point weighting scheme, similar to the sufficiency rating method of evaluating highway pavements, to determine the best interchange configuration. The alternative with the highest numerical "score" is taken as the most appropriate solution. Table 2 is taken from Leisch's article and illustrates this numerical approach for the selection of the proper interchange type, in this example alternative two. One of the noteworthy aspects of Lefsch's methodology is the costs oniy constitute twenty-five percent of the evaluation weight. oglesby, Bishop and Willeke ${ }^{2}$ clearly state the basic problem with most of these before mentioned evaluation techniques.

"A general criticism of these approaches is that they have falled to recognize the two bastc princtples of dectsion making; (a) decisions must be based on the differences among alternatives; and (b) money consequences must be separated from the consequences that are not reducible to money terms, and then the "frreducibles" must be weighed against the money consequences as a part of the dectsion making process".

Grant and 0 glesby ${ }^{3}$ make the following statement in reference to highways and freeways, but it also seems very pertinent to the design of an interchange.

"In many cases some consequences of dectsions among highway alternatives (interchanges) cannot be expressed in terms of money. Furthermore, the "frreducibles" to whomever they may accrue are relevant to the decision. In these situations the "dollar" answers from the economy study do not dictate the final cholce; but on the other hand they provide a money figure against which the frreducibles can be weighed and thereby narrow the area of uncertainty with which the decision maker is faced." 
Mulinazzi and Satterly

TABLE 2 COMPARISON OF ALTERNATIVE

INTERCHANGE SOLUTIONS

Source: 1, p. 21

\begin{tabular}{|c|c|c|c|c|c|c|c|}
\hline \multirow{3}{*}{$\begin{array}{l}\text { Output Variables } \\
\text { (Comparison Items) } \\
\text { (1) }\end{array}$} & \multirow{3}{*}{$\begin{array}{l}\text { Scalc } \\
\text { Value } \\
\text { (2) }\end{array}$} & \multirow{2}{*}{\multicolumn{2}{|c|}{$\overline{1}$}} & \multirow{2}{*}{\multicolumn{2}{|c|}{2}} & \multirow{2}{*}{\multicolumn{2}{|c|}{3}} \\
\hline & & & & & & & \\
\hline & & (3) & (4) & (5) & $(6)$ & (7) & $(8)$ \\
\hline \multicolumn{8}{|l|}{ Operation [30] } \\
\hline $\begin{array}{l}\text { Specds of operation } \\
\text { Travel distance } \\
\text { Safety - compr. E antic. } \\
\text { Safety aspects - other } \\
\text { Capacity }\end{array}$ & $\begin{array}{l}(5) \\
(5) \\
(5) \\
(5) \\
(10)\end{array}$ & $\begin{array}{r}10 \\
10 \\
10 \\
8 \\
10\end{array}$ & $\begin{array}{l}50 \\
50 \\
50 \\
40 \\
100\end{array}$ & $\begin{array}{r}8 \\
9 \\
10 \\
10 \\
8\end{array}$ & $\begin{array}{l}40 \\
45 \\
50 \\
50 \\
80\end{array}$ & $\begin{array}{l}6 \\
7 \\
7 \\
7 \\
6\end{array}$ & $\begin{array}{l}30 \\
35 \\
35 \\
35 \\
60\end{array}$ \\
\hline \multicolumn{8}{|l|}{ Costs [25] } \\
\hline $\begin{array}{l}\text { Capital } \\
\text { Operating }\end{array}$ & $\begin{array}{l}(15) \\
(10)\end{array}$ & $\begin{array}{r}6 \\
10\end{array}$ & $\begin{array}{l}90 \\
100\end{array} \mid$ & $\begin{array}{r}9 \\
10\end{array}$ & 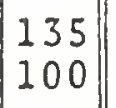 & $\begin{array}{c}10 \\
10\end{array}$ & $\begin{array}{l}150 \\
100\end{array}$ \\
\hline \multicolumn{8}{|l|}{ Implementation [15] } \\
\hline $\begin{array}{l}\text { Construction staging } \\
\text { Maintenance of traf. } \\
\text { Environmental [30] }\end{array}$ & $\begin{array}{l}(10) \\
(5)\end{array}$ & $\begin{array}{l}6 \\
8\end{array}$ & $\begin{array}{l}60 \\
40\end{array}$ & $\begin{array}{l}10 \\
10\end{array}$ & $\left|\begin{array}{lll}1 & 0 & 0 \\
5 & 0\end{array}\right|$ & $\begin{array}{r}8 \\
10\end{array}$ & $\begin{array}{l}80 \\
50\end{array}$ \\
\hline $\begin{array}{l}\text { Traffic disturbances } \\
\text { Aesthetic qualities } \\
\text { Barrier Effect } \\
\text { Impact on develop. }\end{array}$ & $\begin{array}{r}(5) \\
(5) \\
(5) \\
(15)\end{array}$ & $\begin{array}{l}6 \\
6 \\
5 \\
5\end{array}$ & $\begin{array}{l}30 \\
30 \\
25 \\
75\end{array}$ & $\begin{array}{r}10 \\
9 \\
10 \\
9\end{array}$ & $\left|\begin{array}{l}50 \\
45 \\
50 \\
135\end{array}\right|$ & $\begin{array}{r}10 \\
8 \\
7 \\
10\end{array}$ & $\begin{array}{l}50 \\
40 \\
35 \\
150\end{array}$ \\
\hline Total (Index Valuc) & $(100)$ & & 740 & & $930^{*}$ & & 850 \\
\hline (*Bost 11 tornative) & & & & & & & \\
\hline
\end{tabular}


Wattleworth and Ingram ${ }^{4}$ tried to overcome these problems by applying the cost effectiveness methodology to the analysis of alternative interchange design configurations. These authors recognized the "need for a procedure that can be quickly used by a designer to compose alternative interchange design (or redesign) configurations and that considers the cost of each conflguration as well as the effectiveness of the interchange." The effectiveness measure that was used in this research was the total interchange capacity, expressed in terms of equivalent ADT entering the interchange. The cost measure was in terms of the initial costs of the project. Prior to the development of this cost effectiveness approach, the authors formulated a linear programming model to determine interchange capacity. ${ }^{5}$ This linear programming model, itself, would be a good tool to determine the proper interchange configuration, if capacity was the only measure of effectiveness that was used.

During field interviews with interchange designers it became apparent that there is no generally accepted evaluation methodology for the comparison of alternative interchange configurations. In most rural areas there is no problem; diamond interchanges are used most of the time without any comparison to other configurations or without any evaluation of traffic operations, the effect on 1 and use, etc. However, when a decision has to be made because of a complicated design situation, there is no accepted methodology that could be used in the selection of an interchange type. 
Based on these previous comments, an appropriate evaluation methodology for the comparison of alternative interchange configurations must include nonmarket variables as well as market variables. And the best way to incorporate these nonmarket varlabies into an evaluation methodology is through the use of the cost-effectiveness technique.

The appication of the cost-effectiveness approach presented in this paper results in an Effectiveness Profile which is a set of vertical scales; each vertical scale representing a different criterion. For each alternative design, its effectiveness rating for every evaluation criterion is plotted on the proper vertical scale. Straight lines are then drawn connecting the appropriate effectiveness ratings to form an Effectiveness Profile for each alternative configuration. The final Effectiveness Proflle is actually a compilation of two or more cost-effectiveness curves into one graph. The Effectiveness Proflle is an expansion of the community factors profile developed by oglesby, Bishop and willeke 6 as a method for decistons among freeway location alternatives based on user and communtty consequences. Figure 2 is an example of an Effectiveness Profile used to evaluate three alternative interchange configurations.

The effectiveness ratings are measured objectively if posstble - in terms of level of service, acres required, number of families relocated, etc. - or subjectively - poor, fair, good, excellent - based on the designer's experience, and 


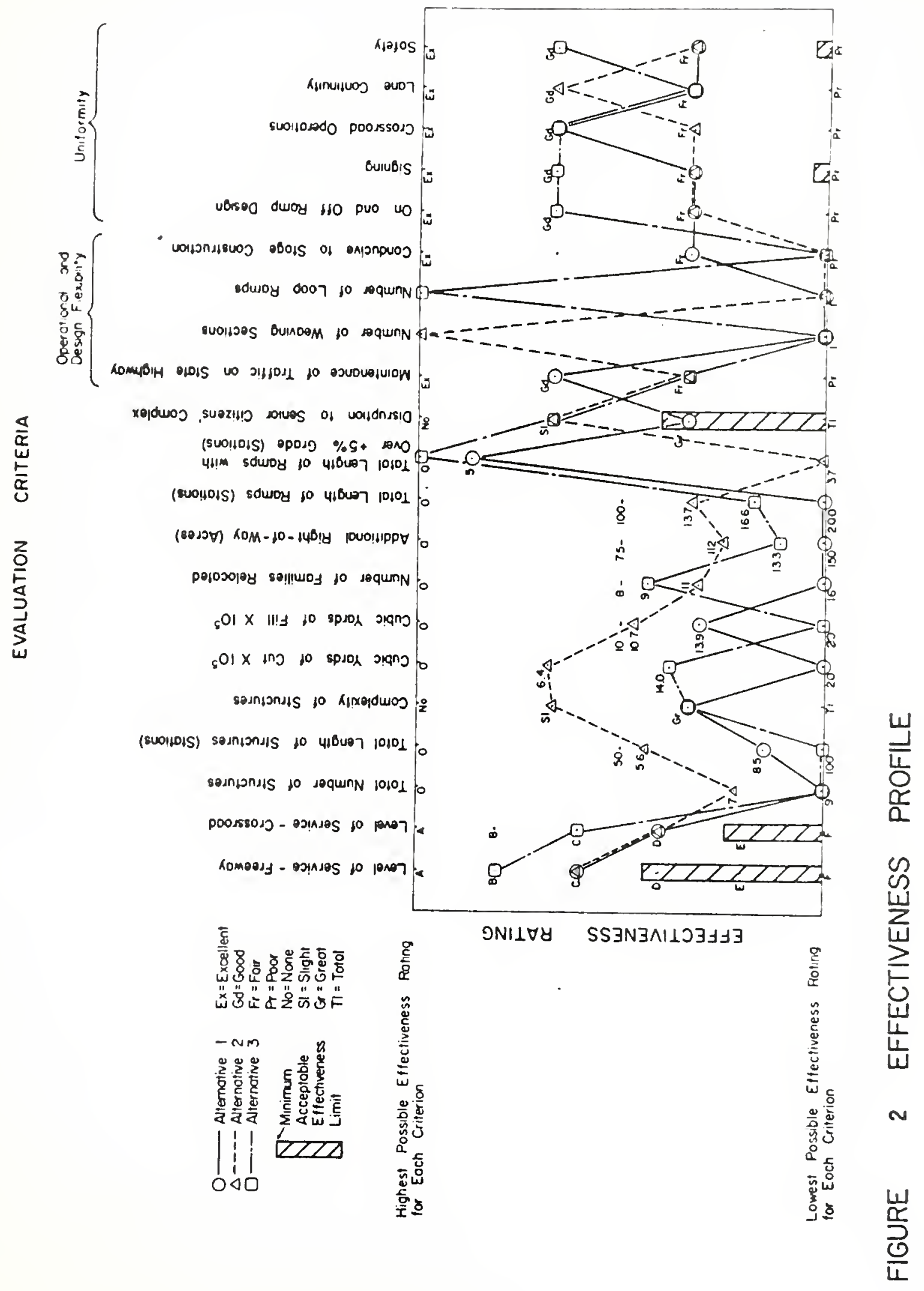


community attitudes. The bottom line of the Effectiveness Profile represents the lowest or worst possible effectiveness rating and the top line the highest or best possible effectiveness rating for each criterion. Each vertical scale is subdivided into equal segments between these two extreme measures of effectiveness. If no predetermined maximum or minimum value can be set for a vertical scale, then the best effectiveness rating for the given alternative designs should be scaled on the top line and the worst effectiveness rating on the bottom line.

Also, some of the evaluation criteria may have a minimum acceptable effectiveness imitation which is more restrictive than the lowest possible effectiveness rating and is represented by a horizontal line across the vertical scales representing those criteria.

If a minimum acceptable effectiveness limit is assigned to an evaluation criterion, it should be done a priori and not after the Effectiveness Profile has been developed. The segment of the vertical scale below this minimum acceptable effectivenes limit is an area which indicates rejection of any alternative whose effectiveness rating falls in it. This rejection of the alternative design should be final unless conditions are changed which either alter the minimum acceptable effectiveness limit or improve the interchange design so that the alternative's effectiveness rating increases above this limiting constraint. For example, in Figure 2, the criteria, level of service on the freeway and on the crossroad and the disruption to the senfor 
citizens' complex, have minimum acceptable effectiveness limits.

The changing of either the minimum acceptable effectiveness limit or the effectiveness rating because of some design alteration lends itseif quite readlly to a rough form of sensitfvity analysis. By making either of these changes, alterations occur relative to the differences between the alternatives, possibly resulting in the selection of a different alternative design.

Evaluation criteria which indicate similar characteristics for the three alternative interchange designs are not included in the Effectiveness Profile; however, they are important in the decision of whether or not an interchange should be constructed. If all three alternative configurations have a simflar positive characteristic, then any of the three types could be bullt, based solely on this factor. But, if all three alternative conflgurations possess the same absolute negative characteristics, then the decision process becomes more complicated. For example, if all three alternatives require the taking of a certain parcel of land which is unattalnable, then there is no feastble alternative among the three given: and efther additional alternative designs must be developed or the total project abandoned.

It is also possible to place confidence limits on the effectiveness ratings for certain subjectively measured criterion. For example, the effectiveness rating for Alternative 1 "for the safety criterion might range from good on the high side to fair on the low side. As long as the confidence limits do not 
intersect a minimum acceptable effectiveness limit, they will show the possible ranges of acceptable effectiveness ratings. If they do go below the minimum level, then a judgment has to be made on the probability of attalning an unacceptable design.

\section{Selection of an interchange Configuration}

In the case of a simple design situation where only one interchange configuration is developed, there is no need for an evaluation methodology since the interchange configuration is already selected. However, when a choice must be made between two or more alternative interchange types, the decision maker, be he the interchange design engineer or his superior, should analyze the Effectiveness Proflle of each alternative design. After eliminating those alternative designs which do not meet all of the minimum attractive effectiveness limits or are dominated by another alternative design, the decision maker is left with the interchange configurations which meet minimum requirements. In the Effectiveness Proflle shown in Figure 2, one of the alternative designs could be quickly eliminated from further consideration. Alternative One causes too much disruption/to the sentor citizen's complex, which is unacceptable to the community. The basic decision, then, is between Alternatives Two and Three. After comparing the inftial cost of each of these remaining interchange types, the decision maker should be able to make a decision on the type of interchange to design. 
This graphical display of alternative consequences, the Effectiveness Profile, should be useful in many ways for the design engineer. It will provide him with an easily understood representation of the overall effects of each alternative design. Besides being an ald to himself and his technical associates, the Effectiveness Profile should be a helpful visual aid at a public meeting, because it clearly illustrates which criteria were used and the effectiveness rating assigned to each alternative for every criteria used. The public may not agree with some of the effectiveness ratings, but at least they will be able to see how the designer arrived at his decision. The public will also be able to visualize the influence of any "absolute" criterion by seeing which alternatives were dropped from further consideration because they did not meet certain minimum attractive effectiveness $11 \mathrm{mit}$.

The Effectiveness Profile could be very useful as an indicator of the monetary value of qualifiable variables. After many interchange design evaluations over a long period of time, it may be possible to look back over the Effectiveness Profiles of past evaluations and formulate a monetary utility for the qualifiable variables or at least recognize which qualifiable criterion carried weight in previous decisions. For example, if a certain evaluation criterion seems to be prevalent when the cheapest design alternative in terms of dollars is not chosen, then it should be possible to assign some dollar value to this criterion. 
The Effectiveness Profile should encourage design variations after the inftial alternatives have been developed. If an alternative meets all of the evaluation criteria except one or two, the declsion maker should feel compelled to see what would happen to the decision outcome if he were to make modifications to the rejected alternative designs so that it would at least meet all of the minimum acceptable effectiveness limits. This procedure will provide the decision maker with a method of evaluating the results of placing certain constraints on the design.

Depending on the selection of evaluation criteria, the Effectiveness Proflle should be sensitive enough to register any significant differences in alternative interchange configurations. The operational differences between a tapered offramp and a parallel off-ramp will not be noticed unless the designer makes this design element one of the evaluation criteria. Significant design variations - a loop ramp versus a diamond type ramp - will definitely register in the Effectiveness Profile.

The strength of the proposed evaluation methodology is contingent on the selection of the evaluation criteria and the deveropment of the Effectiveness Profile. The evaluation methodology is simple to apply and should not require much time. It is felt that these attributes are necessary for the practicing interchange design engineers to use this method in the selection of an interchange configuration. 
NOTES

1. Leisch, Jack. "Determination of Interchange Types on Freeway Facilities: Systems Engineering Approach." Traffic Engineering, Vol. 42, No. 8, May 1972, p. 21.

2. Oglesby, C. H., Bruce Bishop and G. E. Willeke. "A Method for Decisions Among Freeway Location Alternatives Based on User and Community Consequences." Highway Research Board Record 305, Socioeconomic Considerations in Transportation Planning, Washington, D. C., 1970, P..1.

3. Grant, E. L. and C. H. Oglesby. "Economy Studies for Highways." Highway R-search Board Bulletin 306, Washington, D. C., 1961, P. 24 .

4. Wattleworth, 3. A. and J. W. Ingram. "Cost-Effectiveness Technique for Analysis of Alternative Interchange Design Configurations." Highway Research Board Record 390. Geometric Design Implications and Vehicle Noise, Washington, D. C., 1972, P. 27.

5. Wattleworth, J. A. and J.W. Ingram. "A Capacity Analys is Technique for Highway Junctions." (Abridgment), Highway Research Board Record 398. Washington, D. C., 1972, p. 36. 6. Ogiesby, C. H., Bruce Bishop and G. E. Willeke, P. 8. 

